\title{
Fiscal Expenditure, Pricing-to-Market and Exchange Rate Behavior
}

\author{
Chung-Fu Lai ${ }^{1} \&$ Drow-Tai Chen ${ }^{2}$ \\ ${ }^{1}$ Department of Applied Economics, Fo Guang University, Yilan County, Taiwan \\ ${ }^{2}$ Department of Economics, Chinese Culture University, Taipei City, Taiwan \\ Correspondence: Chung-Fu Lai, Department of Applied Economics, Fo Guang University, No. 160, Linwei Rd., \\ Jiaosi, Yilan County 26247, Taiwan (R.O.C.). Tel: 886-3-987-1000. E-mail: cflai@gm.fgu.edu.tw
}

Received: July 17, 2015

Accepted: August 17, 2015

Online Published: September 25, 2015

doi:10.5539/ijef.v7n10p91

URL: http://dx.doi.org/10.5539/ijef.v7n10p91

\begin{abstract}
This paper investigates the effects of fiscal expenditure shock on exchange rate behavior and the role of asymmetric pricing-to-market in the New Open Economy Macroeconomics. The findings of this paper indicated that if discriminatory pricing behavior is considered, and when a country faced with a fiscal expenditure shock, exchange rate fluctuation in the short run would be wider than in the long run with overshooting of exchange rate. Further, the increase of government expenditure will push up exchange rates. If the firms in both countries take pricing based on home (foreign) currency, an enlargement of the size of the home country will cause lesser (wider) range of exchange rate fluctuation with the change in government expenditure. In addition, the greater the effect of the elasticity of substitution among the products and marginal utility of the real money demand will trigger lesser range of exchange rate fluctuation with the change in government expenditure.
\end{abstract}

Keywords: fiscal expenditure, pricing-to-market, new open economy macroeconomics

\section{Introduction}

Obstfeld and Rogoff (1995) proposed the New Open Economy Macroeconomics (henceforth NOEM) to explore the effect and relation of monetary and fiscal policies on exchange rate dynamics. The findings indicated in a symmetrical two-country model, the lack of the factors for exchange rate fluctuation reinforcement and pass-through discouraged overshooting of exchange rate. As such, Obstfeld and Rogoff (1995) suggested in the Appendix to an essay specifically included the role of nontraded goods. They further discovered the possibility of the occurrence of overshooting. Betts and Devereux (1996, 2000) introduced the pricing-to-market (henceforth PTM) behavior for further exploring the relation between monetary policy and exchange rate behavior. The findings indicated that PTM reinforced the influence of monetary policy on exchange rate. Accordingly, the higher the degree of exchange rate fluctuation, the higher the possibility of the occurrence of exchange rate dynamics.

In the NOEM model, personal consumption behavior is the primary cause of exchange rate fluctuation. Yet, the interest of this paper is that in the NOEM model featuring PTM, if we assume consumption behavior includes the consumption behavior of the government, the result will be interesting. As such, the purpose of this paper is to find out the relation between fiscal expenditure, pricing-to-market and exchange rate behavior. To review previous related literature, Tervala (2008) has conducted an analysis on fiscal policy in the NOEM framework. Their result helps to prove that the marginal substitution rate between personal consumption and government consumption is the primary factor affecting fiscal expenditure on welfare effect. Monacelli and Perotti (2006) also studied the impacts of government expenditures shocks in a New Keynesian open-economy model and showed that an increase in public spending produces an ambiguous effect on real exchange rate. However the empirical work by Marialuz Moreno Badia and Alex Segura-Ubiergo (2014) suggests that the fiscal policy has a significant impact on the real exchange rate. But these studies overlooked a familiar topic- the discussion of price discrimination.

According to Betts and Devereux (1996, 2000), if the firms are capable of market segmentation, they can set different prices in different regions, which is known as discriminatory pricing or PTM behaviors. For PTM in the application of NOEM, the works of Devereux and Engel (1998, 2003), Obstfeld (2006), Zhang (2006), Duarte and Obstfeld (2008), Marazzi and Sheets (2007), and Wang and Wu (1996) tend to focus on the discussion of the process of the pass-through of exchange rate to commodity price, which is the role of PTM. Obviously, these 
literatures lead us to know the vital role of PTM in the process of transaction. As such, this paper is an attempt to discuss the effect of the merger of PTM into fiscal expenditure. Betts and Devereux $(1996,2000)$ have marvelously elaborated the role of PTM in the adjustment process of exchange rate dynamics. Still, the assumption of the identical capacity of the firms in both countries in discriminatory pricing ratio cannot explicitly explain the effect on exchange rate if the firms of the two countries have different ratios in discriminatory pricing. Knetter (1993) has compared the PTM ratios of different countries, and discovered that the PTM ratio in Germany was $89 \%$, in Japan was $79 \%$, in the UK was $67 \%$, and in USA was $45 \%$. These indicated the asymmetry of PTM in contemporary international market. The research cannot be deemed successful if this phenomenon is not included in the analysis. As such, this paper is an attempt, based on NOEM in the analysis for revising the symmetric PTM proposed by Betts and Devereux (1996, 2000), to find out the influence of government expenditures in the process of the adjustment of exchange rate dynamics.

The theoretical inference in this paper shows that the increase in government expenditure will push up the exchange rate. If the pricing behavior of the firms in both countries is congruent with the home currency, the enlargement of the size in the home country will trigger lesser fluctuation of the exchange rate with the change in government expenditure. When the pricing behavior of the firms in both countries is congruent with the foreign currency standard, the enlargement of the size in the home country will trigger wider fluctuation of the exchange rate with the change in government expenditure. As for the role of the elasticity of substitution of products and the elasticity of marginal utility of real money demand, we discovered that the stronger the effect of elasticity of the substitution of products and the elasticity of marginal utility of real money demand, the lesser the fluctuation of exchange rate with the change in government expenditure. In this paper, we also proved that if PTM is considered, exchange rate fluctuation in the short run is wider than in the long run with the change in government expenditure, and exchange rate overshooting takes place.

This paper is consisted of 4 sections. In addition to the introduction, the theoretical model setting is proposed in section 2 while the effect of exchange rate fluctuation in the short run and in the long run with the government expenditure and the process of adjustment in exchange rate dynamics is discussed in section 3. Section 4 is the conclusion and recommendation.

\section{The Model}

This paper is presented under NOEM framework of Obstfeld and Rogoff (1995) in the analysis with the extension of a Betts and Devereux (1996). The fundamental assumptions are:

1) There are only two countries in the world, the home country and foreign country.

2) The quantity of the trade goods in the home country distributed in interval $[0, n]$ in continuum while the quantity of trade good in the foreign country distributed in $[1, n]$ in continuum. This represents the size of home country is $n$ and in the foreign country is $1-n$.

3) Each agent is the consumer and the producer. The agent inputs its labor for production. Each agent can produce and consume one unit of heterogeneous trade good.

4) The representative agent is chasing for the maximization of lifetime utility and the agent can share the profit share with the firm.

5) The producers are monopolistic competitors and have the ability in pricing.

6) Commodity price is adherent and cannot changed in the short run, and may only be fully adjusted after certain period of time.

7) In the home country, ratio $s$ of the firms is capable of pursuing discriminatory pricing (PTM) while ratio $1-s$ of the firms is incapable of pursuing discriminatory pricing and ratio $1-s^{*}$ of the firms is incapable of pursuing discriminatory pricing. The ratio of the firms capable of pursuing PTM is different, which is represented by $s \neq s^{*}$.

\subsection{Representative Individuals}

Assuming all individuals have the same preference and the utility of the representative individuals is the function of consumption, real money balance and leisure. The utility function is shown below:

$$
U=\log C+\frac{\gamma}{1-\varepsilon}\left(\frac{M}{P}\right)^{1-\varepsilon}+\eta \log (1-h), \quad \varepsilon>0
$$

Where $C$ is the consumption index, $M / P$ is the real money balance, $h$ is the total work hours, $\varepsilon$ is the elasticity of marginal utility of real money balance, and $\gamma$ and $\eta$ represent the degree of importance of the 
function of real money balance currency and leisure (Note 1).

In Eq. (1), the consumption index of the representative individual is defined as the function of constant elasticity of substitution (CES) form, which is shown below:

$$
C=\left[\int_{0}^{n} c(z)^{\frac{\rho-1}{\rho}} d z\right]^{\frac{\rho}{\rho-1}}, \rho>1
$$

Where $c(z)$ is the consumption of particular product $z$ by the consumers of the home country, and $\rho$ represents the elasticity of substitution between two products. (Note 2)

As defined by Eq. (2), we could deduce that domestic price index $(P)$ under PTM as:

$$
P=\left[\int_{0}^{n} p(z)^{1-\rho} d z+\int_{n}^{n+(1-n) s^{*}} p_{f}(z)^{1-\rho} d z^{*}+\int_{n+(1-n) s^{*}}^{1}\left(E p_{f}^{*}(z)\right)^{1-\rho} d z\right]^{\frac{1}{1-\rho}}
$$

Likewise, the foreign price index $\left(P^{*}\right)$ is:

$$
P^{*}=\left[\int_{0}^{n s} p^{*}(z)^{1-\rho} d z+\int_{n s}^{n}(p(z) / E)^{1-\rho} d z+\int_{n}^{1} p_{f}^{*}(z)^{1-\rho} d z^{*}\right]^{\frac{1}{1-\rho}}
$$

In the above two equations, the symbols are defined as: $p(z)$ represents the price of home product $z$ denominated by home currency; $p_{f}(z)$ represents the price of foreign products z denominated by home currency with foreign firms are able to PTM, $p_{f}^{*}(z)$ the price of foreign products $\mathrm{z}$ denominated by foreign with firms adopt producer-currency pricing $(\mathrm{PCP}), p^{*}(z)$ represents the price of home product $z$ denominated by foreign currency with firms are able to PTM, and $E$ is the nominal exchange rate.

From Eqs. (2) and (3), we could deduce that the consumption of particular product $\mathrm{z}$ of the representative consumers as: (Note 3 )

$$
c(z)=\left[\frac{\xi(z)}{P}\right]^{-\rho} C
$$

Where $\xi(z)=p(z), p_{f}(z)$ and $E p_{f}^{*}(z)$, and represent the price of particular home product $z$ denominated by home currency, the price of particular foreign PTM product $z$ denominated by home currency, and the price of particular foreign PCP product $z$ in denominated by home currency, respectively.

Likewise, the consumption of particular product by the foreign representative consumer is:

$$
c^{*}(z)=\left[\frac{\varsigma(z)}{P^{*}}\right]^{-\rho} C^{*}
$$

Where $C^{*}$ is the foreign consumption index, $c^{*}(z)$ is the consumption of particular product $z$ by foreign consumers, $\varsigma(z)=p_{f}^{*}(z), p^{*}(z)$, and $p(z) / E$ represent the price of particular foreign product $z$ denominated by foreign currency, the price of particular home PTM product $z$ denominated by foreign currency, and the price of particular home PCP product $z$ denominated by foreign currency.

The budget constraint for the home representative individuals is: 


$$
P C+M=W h+\pi+M_{0}+T R
$$

Eq. (7) represents the sources of incomes for the representative individuals: including wage incomes (Wh), share of profit from domestic firms $(\pi)$, transfer income of the government $(T R)$ and money balance from the previous period $\left(M_{0}\right)$ where the incomes are disposable for consumption $(P C)$ and keeping currency $(M)$.

Under budget constraints (Eq. (7)), the representative consumers will chase for maximization of utility (Eq.(1)) with the optimal first-order conditions as follow:

$$
\begin{gathered}
\frac{M}{P}=(\gamma C)^{1 / \varepsilon} \\
\frac{\eta}{1-h}=\frac{W}{P C}
\end{gathered}
$$

Where Eq. (8) is the equation of money demand that showing the behavior of the individuals in demand for real money. Eq. (9) is the equation for labor supply determining the substitution relation between the labor supply and consumption.

Likewise, in the foreign country, there are:

$$
\begin{gathered}
\frac{M^{*}}{P^{*}}=\left(\gamma C^{*}\right)^{1 / \varepsilon} \\
\frac{\eta}{1-h^{*}}=\frac{W^{*}}{P^{*} C^{*}}
\end{gathered}
$$

Eq. (10) is the equation of money demand in the foreign country, Eq. (11) is the equation of labor supply in the foreign country.

\subsection{Government}

Assuming the government and the private sector have the same preference and the government expenditure function is also follow the form of CES,

$$
G=\left[\int_{0}^{1} g(z)^{\frac{\rho-1}{\rho}} d z\right]^{\frac{\rho}{\rho-1}}
$$

Where $g(z)$ represents the consumption of the government sector on particular product $z$.

And, assuming the budget constraint of government is:

$$
P G+T R=M-M_{0}
$$

Where government expenditures include consumption spending $(P G)$ and transfer payment $(T R)$, and government finances its expenditure by issuing money $\left(M-M_{0}\right)$.

\subsection{Firms}

Assuming labor is the only factor of production, the production behavior of the firm is:

$$
y(z)=A h(z)
$$

Eq. (14) is the production function of domestic firms, where $y(z)$ represents the production of product $z$ by the firms and $h(z)$ is the labor employment of the firms while $A$ represents the productivity shock of the home country and is a constant.

There are two types of firms. One is capable of pursuing PTM and set different prices in different markets. Another is incapable of pursuing PTM and set one price for products selling in the home country or in the foreign country. For the firms $z$ pursuing PTM, we have:

$$
y(z)=(c(z)+g(z))+\left(c^{*}(z)+g^{*}(z)\right)
$$

Where $c(z)+g(z)$ is the quantity of PTM products of the home country selling domestically (pricing as $p(z))$; and $c^{*}(z)+g^{*}(z)$ is the quantity of PTM products of the home country selling to foreign country (pricing as $p^{*}(z)$ ). 
The function of profit for domestic firms pursuing PTM is:

$$
\pi(z)=p(z)(c(z)+g(z))+E p^{*}(z)\left(c^{*}(z)+g^{*}(z)\right)-\frac{W}{A}\left((c(z)+g(z))+\left(c^{*}(z)+g^{*}(z)\right)\right)
$$

If we impute Eq. (5) to the above equation and to derive first-order-condition, the pricing level of the firms in maximization of profit is:

$$
p(z)=E p^{*}(z)=\frac{\rho}{\rho-1} \frac{W}{A}
$$

Eq. (15) explains that pricing of the firms under monopolistic competition is made based on wages with a markup.

The price index in the home country (Eq. (3)) and in the foreign country (Eq.(4)) can be simplified as:

$$
\begin{aligned}
& P=\left[n p(z)^{1-\rho}+(1-n) s^{*} p_{f}(z)^{1-\rho}+(1-n)\left(1-s^{*}\right) E p_{f}^{*}(z)^{1-\rho}\right]^{\frac{1}{1-\rho}} \\
& P^{*}=\left[n s p^{*}(z)^{1-\rho}+n(1-s)(p(z) / E)^{1-\rho}+(1-n) p_{f}^{*}\left(z^{*}\right)^{1-\rho}\right]^{\frac{1}{1-\rho}}
\end{aligned}
$$

\section{Solve for Equilibrium}

In this section, we derive the equilibrium solutions with flexible prices in the long-run and price rigidity in the short-run, respectively, and focus on the analysis in the issues of fiscal expenditure and PTM. In the long-run with flexible-prices, price can be adjusted freely and all variables reached steady state equilibrium. While in the short-run with sticky-price, price is rigid, the commodity prices cannot be adjusted immediately and will cause the dynamic adjustment of the economic system.

\subsection{Equilibrium with Flexible Prices}

Where price is freely adjustable, all markets can achieve equilibrium. At this time, the consumption level in the equilibrium could be represented by:

$$
\begin{gathered}
C+G=A h=y \\
C^{*}+G^{*}=A h^{*}=y^{*}
\end{gathered}
$$

To substitute Eq. (15) into Eq.(11) and make use of Eq. (18), we could get the labor employment of the home country $(h)$ as:

$$
h=\frac{(\rho-1) / \rho}{((\rho-1) / \rho)+\eta}
$$

The equilibrium exchange rate in the long run can be obtained from Eqs. (8) and (10): (Note 4)

$$
E=\frac{M}{M^{*}}\left(\frac{C^{*}}{C}\right)^{\frac{1}{\varepsilon}}
$$

From the above equation, we could see that: if price is freely adjustable, PTM will not affect consumption, labor input, and exchange rate level in the long run.

\subsection{Equilibrium with Sticky Price}

Under sticky-price equilibrium, price is rigid and cannot be adjusted. At this time, the condition of equilibrium in the money market is shown in Eqs. (8) and (10). And, output is determined by demand in the short run, as such, the conditions of equilibrium in the product market in the home country and in the foreign country are:

$$
\begin{aligned}
& y(z)=\left(\frac{p(z)}{P}\right)^{-\rho} n(c(z)+g(z))+\left(\frac{E p^{*}(z)}{P^{*}}\right)^{-\rho}(1-n)\left(c^{*}(z)+g^{*}(z)\right) \\
& y^{*}(z)=\left(\frac{p_{f}(z)}{E P}\right)^{-\rho} n(c(z)+g(z))+\left(\frac{p_{f}^{*}(z)}{P^{*}}\right)^{-\rho}(1-n)\left(c^{*}(z)+g^{*}(z)\right)
\end{aligned}
$$


To substitute Eq.(13) into Eq.(7) in consideration of PTM behavior, we could come up with the constraints for the households in the home country and in the foreign country in the short run as specified below:

$$
\begin{gathered}
P C=n(1-s) p(z) y(z)+n s\left(p(z)(c(z)+g(z))+E p^{*}(z)\left(c^{*}(z)+g^{*}(z)\right)\right. \\
P^{*} C^{*}=(1-n)\left(1-s^{*}\right) p_{f}^{*} y^{*}(z)+(1-n) s^{*}\left(\frac{p_{f}(z)}{E}(c(z)+g(z))+p_{f}^{*}(z)\left(c^{*}(z)+g^{*}(z)\right)\right)
\end{gathered}
$$

The left side of Eq. (24) represents the consumption spending of the households, and the right side of Eq. (24) represents the sources of incomes, including the incomes from PTM outputs $(n(1-s) p(z) y(z))$ and incomes from PCP outputs $\left(n s\left(p(z)(c(z)+g(z))+E p^{*}(z)\left(c^{*}(z)+g^{*}(z)\right)\right)\right.$. Eq. (25) is the budget constraint of the foreign households.

Owing to the complexity of the above model, there are two ways for getting closed-form solution for the endogenous and the exogenous variables; 1.log-linearization, and 2.numerical simulations. In this paper, the $\log$-linearization method is adopted for simplicity in the analysis.

In the following equations, the superscript “^” represents the value of each variable after log-linearization. For example: $\hat{X}_{t}$ is the result of $\log$-linearization of variable $X_{t}$ at initial state $X_{0}$, which is:

$$
\hat{X}_{t}=\frac{X_{t}-X_{0}}{X_{0}}=\frac{d X_{t}}{X_{0}}=\ln \left(\frac{X_{t}}{X_{0}}\right)
$$

In the short run, due to price rigidity $\left(\hat{p}(z)=\hat{p}^{*}(z)=\hat{p}_{f}(z)=\hat{p}_{f}^{*}(z)=0\right)$. The price indices in the home country and in the foreign country after log-linearization (Eq. (3) and Eq. (4)) are:

$$
\begin{gathered}
\hat{P}=(1-n)\left(1-s^{*}\right) \hat{E} \\
\hat{P}^{*}=-n(1-s) \hat{E}
\end{gathered}
$$

From Eqs. (26) and (27), we could see that: The higher the ratio of foreign firms in pursuing PTM or the smaller the size of the foreign country, the lower the pass-through effect of exchange rate on the price in the home country. The higher the ratio of domestic firms in pursuing PTM or the smaller the size of the home country, the lower the pass-through effect of the exchange rate on the price in the foreign country. Indeed, if both the domestic and the foreign firms pursue PTM, no pass-through effect of the exchange rate at all.

To subtract Eq. (28) from Eq. (29), we could get:

$$
\hat{P}-\hat{P}^{*}=\left[(1-n)\left(1-s^{*}\right)+n(1-s)\right] \hat{E}
$$

From Eq. (28), we could see that the size of the country and the ratio of PTM will condition the effect of exchange rate on the relative prices of two countries. If we take two extreme examples with the trade goods of both countries were priced in home currency (which is $s=0 ; s^{*}=1$ ), as defined by Devereux et al. (2007) as the pricing behaviors of the firms in both countries are denominated in home currency standard system, the greater the enlargement of the size of the home country, the smaller the effect of exchange rate on the relative prices of the two countries. If the trade goods of the two countries are priced based on the foreign currency (which is $s=1 ; s^{*}=0$ ), the pricing behaviors of the firms in the two countries are based on foreign currency standard system. At this point, the greater the enlargement of the size of the foreign country, the smaller the effect of exchange rate on the relative prices of the two countries.

\subsection{Government Expenditure and Exchange Rate Behavior}

Take the log-linearization of the money market equilibrium condition (Eq. (8) and Eq. (10)) and subtract from each other, we get: 


$$
\hat{M}-\hat{M}^{*}=\hat{P}-\hat{P}^{*}+\frac{1}{\varepsilon}\left(\hat{C}-\hat{C}^{*}\right)
$$

To substitute Eq. (28) into Eq. (29) and tidy up the two, we have:

$$
\hat{E}=\frac{1}{\left[(1-n)\left(1-s^{*}\right)+n(1-s)\right]}\left[\left(\hat{M}-\hat{M}^{*}\right)-\frac{1}{\varepsilon}\left(\hat{C}-\hat{C}^{*}\right)\right]
$$

Eq. (30) is the determination of exchange rate under the monetary analysis approach. This equation specifies that exchange rate is determined by the change in relative money supply and relative consumption between two countries, and subject to the influence of the size of the country and ratio of PTM.

The relative consumption item of the two countries $\left(\hat{C}-\hat{C}^{*}\right)$ as shown in Eq. (30) cannot fully present with the function of exogenous variables. As such, exchange rate level is not the final solution and we will not go further in the discussion. But, if we compare Eq. (30) and Eq. (21) after log-linearization, we could see that the exchange rate will exhibit overshooting adjustment, which implies that under the monetary shock, exchange rate fluctuation in the short run will be wider than the fluctuation in the long run (Note 5).

To subtract Eq. (24) from Eq. (25) with log-linearization, and imputes the result into Eqs. (5), (6), and (28), we could see the response of exchange rate in the short run as:

$$
\hat{E}=\frac{(\hat{C}+\hat{G})-\left(\hat{C}^{*}+\hat{G}^{*}\right)}{\left[(1-n)\left(1-s^{*}\right)+n(1-s)\right](\rho-1)+\left(n s+(1-n) s^{*}\right)}
$$

Eq. (31) shows the relation between exchange rate and the consumption (including the households and the governments) in the two countries. Similar analysis indicated that, when the pricing behaviors of the firms in both countries are denominated in home currency (which is $s=0 ; s^{*}=1$ ), the greater the enlargement of the size of the home country, the smaller the effect of exchange rate on the relative consumption of the two countries. If the pricing behavior of the firms in the two countries is based on the foreign currency (which is $s=1$; $s^{*}=0$ ), the greater the enlargement of the size of the home country, the higher the effect of exchange rate on the relative consumption of the two countries. If the ratios of PTM of the two countries are equal $\left(s=s^{*}\right)$, we go back to the conclusion of Betts and Devereux (1996).

In combining Eqs. (30) and (31), we get: (Note 6)

$$
\hat{E}=\frac{\hat{G}-\hat{G}^{*}}{\left[(1-n)\left(1-s^{*}\right)+n(1-s)\right](\varepsilon+\rho-1)+\left(n s+(1-n) s^{*}\right)}
$$

From Eq. (32), we could see that an increase of government spending will push up exchange rate. When the pricing behavior of the firms in both countries are denominated in home currency $\left(s=0 ; s^{*}=1\right)$, the greater the enlargement of the size of the home country, the lesser the fluctuation of exchange rate with the change in government spending. When the pricing behavior of the firms in both countries are denominated in foreign currency $\left(s=1 ; s^{*}=0\right)$, the greater the enlargement of the size of the home country, the wider the fluctuation of exchange rate with the change in government spending and because $\rho>1$, the higher the elasticity of substitution of products and the elasticity of the marginal utility of real money demand, the lesser the fluctuation of exchange rate with the change in government spending.

\section{Conclusion and Recommendation}

Literatures in the past have pointed out the role of PTM behavior of the process in which monetary policy affects exchange rate. Yet, they are confined to the discussion of symmetric PTM behavior and the impact of monetary shock, but cannot explain the effects of government spending while an economic system exists asymmetric discriminatory. For these reasons, suppose the change in each country's money supply are consistent, this paper attempts, based on the framework of NOEM, to extend the PTM model of Betts and Devereux (1996) into the setup of the fiscal expenditure and asymmetric PTM with the findings served as reference for the authorities in policy decision-making.

From the theoretical inference, this paper shows that when the country faces a fiscal expenditure shock, if takes discriminatory pricing, the exchange rate fluctuation in the short run will be stronger than in the long run and exchange rate will exhibit overshooting. Furthermore, an increase of government spending will push up the 
exchange rate, if the firms in both countries are pricing in home currency, the greater the enlargement of the size of the home country, the lesser the fluctuation of exchange rate with the change in government spending; if the pricing behavior of the firms in both countries are denominated in foreign currency, the greater the enlargement of the size of the home country, the wider the fluctuation of exchange rate with the change in government spending. And, the higher the elasticity of substitution of products and the elasticity of the marginal utility of real money demand, the lesser the fluctuation of exchange rate with the change in government spending.

Finally, we would like to put forward that NOEM has highlighted its contribution to different topics in economics. However, as the theoretical foundation, NOEM shall be subject to the testing under various hypotheses to give specific inference. If we ease one of the hypotheses or equations, the results may be opposite from the initial conclusion. We feel these constraints in this paper.

\section{References}

Betts, C., \& Devereux, M. B. (1996). The exchange rate in a model of pricing-to-market. European Economic Review, 40, 1007-1021. http://dx.doi.org/10.1016/0014-2921(95)00110-7

Betts, C., \& Devereux, M. B. (2000). Exchange rate dynamics in a model of pricing-to-market. Journal of International Economics, 50, 215-244. http://dx.doi.org/10.1016/S0022-1996(98)00036-1

Devereux, M., \& Engel, C. (1998). Fixed v.s. flexible exchange rates: How price setting affects the optimal choice of exchange-rate regime. NBER Working Paper No. 6867. http://dx.doi.org/10.2139/ssrn.144912

Devereux, M., \& Engel, C. (2003). Monetary policy in the open economy revisited: Price setting and exchange rate flexibility. Review of Economic Studies. 70, 765-783. http://dx.doi.org/10.1111/1467-937X.00266

Devereux, M., Shi, K., \& Xu, J. (2007). Global monetary policy under a dollar standard. Journal of International Economics, 71, 113-132. http://dx.doi.org/10.1016/j.jinteco.2005.12.007

Duarte, M., \& Obsstfeld, M. (2008). Monetary policy in the open economy revisited: The case for exchange-rate flexibility restored. Journal of International Money and Finance. 27(6), 949-957. http://dx.doi.org/10.1016/j.jimonfin.2008.04.007

Knetter, M. M. (1992). International comparisons of pricing-to-market behavior. NBER Working Paper No. 4098. http://dx.doi.org/10.3386/w4098

Marazzi, M., \& Sheets, N. (2007). Declining exchange rate pass-through to U.S. import prices: The potential role of global factors. Journal of International Money and Finance, 26, 924-947. http://dx.doi.org/10.1016/j.jimonfin.2006.12.003

Marialuz, M. B., \& Alex, S. U. (2014). Real exchange rate appreciation in emerging markets: Can fiscal policy help? IMF Working Paper No. 14/1. http://dx.doi.org/10.5089/9781475523577.001

Monacelli, T., \& Perotti, R. (2006). Fiscal policy, the trade balance and the real exchange rate: Implications for international risk sharing. Working Paper, IGIER, Universita Bocconi.

Obstfeld, M. (2006). Pricing-to-market, the interest-rate rule, and the exchange rate. NBER Working Paper No. 12699. http://dx.doi.org/ 10.3386/w12699

Obstfeld, M., \& Rogoff, K. (1995). Exchange rate dynamics redux. Journal of Political Economy, 103, 624-660. http://dx.doi.org/10.1086/261997

Tervala, J. (2008). Productive government spending, welfare and exchange rate dynamics. Financial Theory and Practice, 32, 97-114.

\section{Notes}

Note 1 . The elasticity of marginal utility of real money balance is defined as the response of the change in the marginal utility of real money balance under a change of $1 \%$ real money balance.

Note 2. $\rho$ represents the degree of response of the consumption ratio of two commodities to a change of $1 \%$ of the marginal rate of substitution.

Note 3. Eq. (5) can be derived by the following maximization problem and using the Eq. (3)-to get by the expenditure minimization.

$$
\max _{c(z)} C=\left[\int_{0}^{1} c(z)^{\frac{\rho-1}{\rho}} d z\right]^{\frac{\rho}{\rho-1}} \text { subject to } \int_{0}^{1} p(z) c(z) d z=Z
$$


Note 4. The same as Betts and Devereux (1996). From Eq. (15), we can see purchasing power price parity in the long run can be established.

Note 5. In Eq. (30), $\left[(1-n)\left(1-s^{*}\right)+n(1-s)\right]<1$.

Note 6. Assuming $\hat{M}-\hat{M}^{*}=0$.

\section{Copyrights}

Copyright for this article is retained by the author(s), with first publication rights granted to the journal.

This is an open-access article distributed under the terms and conditions of the Creative Commons Attribution license (http://creativecommons.org/licenses/by/3.0/). 